\title{
A melhoria contínua em uma fábrica de pão de queijo de São Paulo: Um estudo de
}

\section{caso}

\author{
Continuous improvement in a cheese bread factory in São Paulo: A case study
}

Mejora continua en una fábrica de pan de queso en São Paulo: Un estudio de caso

\author{
Recebido: 15/05/2021 | Revisado: 21/05/2021 | Aceito: 25/05/2021 | Publicado: 09/06/2021 \\ Evaldo Ferreira De Sousa \\ ORCID: https://orcid.org/0000-0001-7236-5963 \\ Instituto Federal de Educação, Ciência e Tecnologia de São Paulo, Brasil \\ E-mail: evaldosousa1975@gmail.com \\ Cristina Corrêa de Oliveira \\ ORCID: https://orcid.org/0000-0002-8629-6679 \\ Instituto Federal de Educação, Ciência e Tecnologia de São Paulo, Brasil \\ E-mail: crisolive@ifsp.edu.br
}

\begin{abstract}
Resumo
O mercado está se tornando progressivamente mais competitivo, o que torna a continuidade de uma organização mais trabalhosa, pois para assegurar sua fatia de mercado ela deve se manter competitiva, com melhoria contínua no processo fabril e nos resultados. Este estudo desenvolveu um estudo do processo produtivo de uma pequena empresa produtora de pão de queijo, na cidade de São Paulo. Foi realizado um estudo de caso, iniciado com uma pesquisa sobre o processo produtivo da empresa, tendo como pressuposto um levantamento bibliográfico sobre o processo e a filosofia Kaizen, em conjunto com as ferramentas 3Ms e Matriz de GUT. Foram considerados os dados quantitativos e qualitativos que permitiram analisar os pontos de vulnerabilidade da empresa e necessidade de melhorias. Foram detectados pontos de melhoria no processo produtivo, especificamente no rearranjo físico, com movimentação desnecessária de materiais e pessoas, bem como de manutenção nos fornos. A partir das ferramentas utilizadas, foi possível mapear o processo produtivo, encontrar os maiores problemas e trabalhar em parceria com os funcionários e o proprietário para implementar soluções otimizadas para a empresa com redução da movimentação e aumento da produção.
\end{abstract}

Palavras-chave: Kaizen; Produtividade; Melhoria contínua.

\begin{abstract}
The market is becoming progressively more competitive, which makes the continuity of an organization more difficult, because to ensure its market share it must remain competitive, with continuous improvement in the manufacturing process and results. This study developed a study of the production process of a small cheese bread production company in the city of São Paulo. A case study was carried out, initiated with research on the company's production process, with the assumption of a bibliographic survey on the Kaizen process and philosophy, in conjunction with the 3Ms and GUT Matrix tools. Quantitative and qualitative data were considered, which allowed the analysis of the company's points of vulnerability and the need for improvement. Points of improvement were detected in the production process, specifically in the physical rearrangement, with the unnecessary movement of materials and people, as well as maintenance in the furnaces. From the tools used, it was possible to map the production process, find the biggest problems and work in partnership with the employees and the owner to implement optimized solutions for the company with reduced handling and increased production.
\end{abstract}

Keywords: Kaizen; Productivity; Continuous improvement.

\section{Resumen}

El mercado se vuelve cada vez más competitivo, lo que dificulta la continuidad de una organización, pues para asegurar su participación de mercado debe seguir siendo competitiva, con mejora continua en el proceso de fabricación y resultados. Este estudio desarrolló un estudio del proceso de producción de un pequeño productor de pan de queso en la ciudad de São Paulo. Se realizó un estudio de caso, partiendo de una investigación sobre el proceso productivo de la empresa, con la asunción de un relevamiento bibliográfico sobre el proceso y la filosofía Kaizen, junto con las herramientas 3Ms y GUT Matrix. Se consideraron datos cuantitativos y cualitativos que permitieron analizar los puntos de vulnerabilidad de la empresa y la necesidad de mejora. Se detectaron puntos de mejora en el proceso productivo, específicamente en la reordenación física, con movimientos innecesarios de materiales y personas, así como mantenimiento en los hornos. A partir de las herramientas utilizadas, fue posible mapear el proceso de producción, encontrar los mayores problemas y trabajar en asociación con los empleados y el propietario para implementar soluciones optimizadas para la empresa con un manejo reducido y una mayor producción.

Palabras clave: Kaizen; Productividad; Mejora continua. 


\subsection{Introdução}

Em um contexto de incertezas e riscos, as empresas tendem a ter uma maior preocupação em reduzir custos (Silveira, 2014), diminuindo, principalmente, a quantidade de funcionários do seu quadro organizacional, cortando consequentemente suas despesas. No entanto a escola japonesa de administração demonstrou ser um contraponto com novas concepções e metodologias para o processo produtivo. O foco era a busca pela melhoria continua na organização e, junto dela, alcançar a qualidade total (Araújo \& Rentes, 2006).

Conforme Araújo e Rentes (2006), uma das ferramentas criada por eles está voltada para a eliminação dos desperdícios e, assim, obter a redução de custos. Desse modo, nasceu a filosofia Kaizen, sustentada pelo princípio de eliminar o desperdício de processos e focar na melhoria contínua.

Este artigo apresenta uma discussão cujos conceitos de filosofia Kaizen em paralelo com os elementos 3M's e 5S's. Com base nesse estudo, foram priorizadas três propostas de melhorias para a pequena fábrica de pão de queijo, situada na cidade de Guarulhos, no estado de São Paulo, que aceitou o estudo desde que não fosse identificada, doravante denominada de Sousa. Em um primeiro momento, foi realizado um mapeamento dos processos organizacionais e tendo como resultado um diagnóstico empresarial que serviu para sistematizar a coleta dos dados, visando gerar um aumento de produtividade ao remodelar o processo, excluindo os desperdícios. A importância desta filosofia é a aplicação dela em toda organização empresarial

\subsection{A Filosofia Kaizen no Lean Manufacturing}

Atualmente, a concepção de Lean Manufacturing (LM) ou Manufatura Enxuta, tem na sua origem o Sistema de Produção das Toyota, criado no Japão, a partir da Segunda Guerra Mundial e acabou por revolucionar o setor produtivo do mundo inteiro. Havia uma necessidade de renovação dos ultrapassados modelos gerenciais, otimizando o aproveitamento dos recursos produtivos, e enfrentar a retração do mercado, alterando o processo produtivo (Womack, 2007). Uma LM é perfeita para expressar a necessidade de melhorar a qualidade, reduzir os desperdícios e o tempo de entrega ao cliente (Liker, 2006). Dessa forma, a empresa adquire maior flexibilidade e agilidade na execução dos seus processos, conforme a Figura 1, pois apresenta os dois pilares do LM, o Just in Time, que é um sistema de administração da produção onde se aplica a filosofia de que não se deve produzir, transportar ou comprar antes da hora certa.

O pilar Jidoka está relacionado com o processo de automação, com um toque humano, ou seja, tanto os operadores quanto às máquinas conseguem detectar falhas e interromper imediatamente a produção. Além disso, estão sustentados pelo trabalho padronizado (Heijunka) e a filosofia Kaizen.

Algumas das metodologias do LM são bem mais conhecidas, como o Kanban, o Planejar, Fazer, Controlar e Agir conhecido como ciclo PDCA, os 5 S's, os 5 Por Quês, os 5W e 2H, Poka-Yoke, e Takt-time. Outras são menos conhecidas como o Heijunka Box, Mapeamento do Fluxo de Valor, Milk Run e Andon, porém todas buscam a adequação do sistema produtivo à filosofia LM. 
Figura 1 - Casa do Sistema Toyota de Produção.

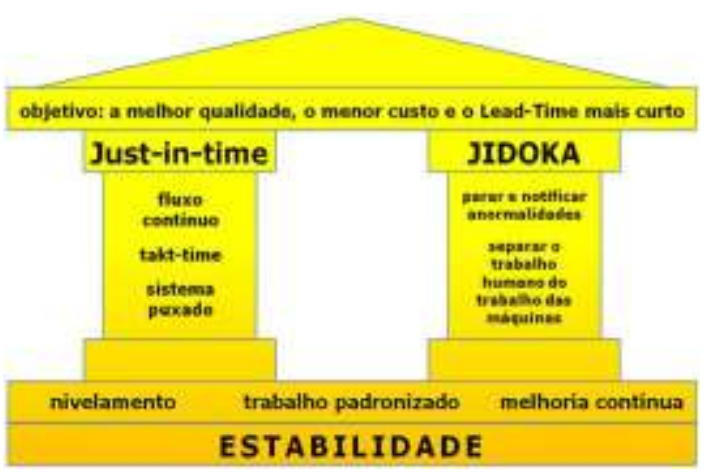

Fonte: Kondrasovas (2020).

\subsection{O significado da filosofia Kaizen}

O termo Kaizen, originalmente japonês, significa melhoria contínua, é a ideia de uma melhoria que envolve todos os departamentos e pessoas de uma organização, desde gerentes até os trabalhadores. Para Sharma, Sharma e Singh (2015), o termo é uma visão que tem seu foco em melhorar um lugar de trabalho ou uma organização em etapas incrementais.

De acordo com Imai (1996) Kaizen é uma filosofia muito comum na cultura japonesa, que abarca todos os setores da vida em sociedade. Além disso, não tem por objetivo grandes melhorias para obter grandes resultados. De fato, o seu propósito é agir em qualquer melhoria, seja de que tipo for e do seu tamanho. A ideia, predominante, é a aplicação de pequenas melhorias na rotina diária de uma empresa, sendo que o resultado final será a somatórias destas ações.

Essa é uma proposta que muda a perspectiva de ação da gerência das empresas do mundo ocidental, que prioriza os momentos de grandes revoluções e inovações. Por isso entendem a inovação como uma mudança drástica, que obrigatoriamente implica em grandes investimentos em tecnologia e equipamentos. Sehleanu e Flore (2015) complementam que, no Japão, esta filosofia envolve a criatividade do trabalhador determinando que os funcionários sejam proativos e promovam mudanças e inovação no seu espaço de trabalho.

Shingo (2005) esclarece que o Kaizen é muito mais sutil, pois prioriza os processos desenvolvidos a partir dos esforços das pessoas, da moral, do envolvimento e da autodisciplina. Ao lado disso, se colocam os aspectos da comunicação, do treinamento, dos trabalhos em equipe. Por isso, o foco do Kaizen é uma mudança contínua, diariamente sendo conduzida para acumular resultados positivos. Uma variável a ser considerada é a redução de custos, pois conforme Ohno (1997, p. 45) ela apresenta resultados fundamentados na ideia de que as pessoas podem e, devem melhorar continuamente as suas atividades laborais. A segunda variável é o aumento da produtividade, estabelecidos como metas a serem alcançadas, Huntzinger (2005) complementa que para que o Kaizen seja aplicado é preciso que a empresa tenha uma meta a alcançar, pois sem está a metodologia fica parecendo com um barco à deriva. Os esforços devem ser direcionados para se alcançar um determinado objetivo, que será o orientador de todo o processo a ser desenvolvido e das melhorias dos processos a serem implementadas continuamente.

O Kaizen deve ser compreendido pelas empresas como um método de resolução de problemas, (Imai, 1996, p. 25) "para que um problema possa ser entendido e resolvido corretamente, é preciso reconhecê-lo e depois coletar e analisar os dados relevantes".

A coleta de dados deve ser realizada com uma observação in loco (Ohno,1997), ou uma Gemba, que significa ir até o local do problema para estudá-lo. Da mesma forma que uma ideia de melhoria não se faz em uma mesa de escritório, obrigatoriamente tem que envolver o chão de fábrica para identificar efetivamente os problemas e as causas dos problemas.

Ainda, conforme Imai (1996), a atividade do Gemba é utilizada no Kaizen como forma de estimular o funcionário a pensar a respeito dos problemas e das suas possíveis soluções. Com isso a coleta de dados é realizada e os pontos chaves 
podem ser encontrados com maior facilidade, utilizando ferramentas tais como o PDCA e as ferramentas de qualidade.

\subsection{Os 3Ms (Muda, Mura e Muri)}

$\mathrm{Na}$ base da concepção da filosofia Kaizen está a fundamentação da ideia de eliminar os desperdícios e reduzir despesas, conforme pode ser visto na Figura 2. É preciso compreender os 3Ms japoneses da produção enxuta Silveira (2014), ou seja, Muda, Mura e Muri.

Figura 2 - Muda, Mura e Muri.

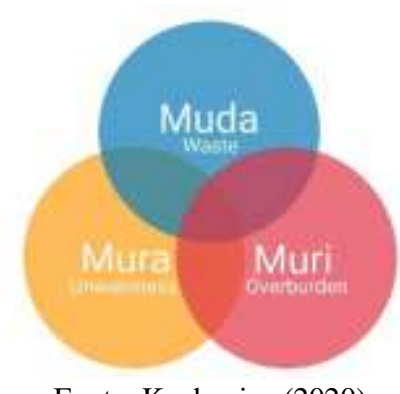

Fonte: Kanbanize (2020).

O termo Muda refere-se a toda atividade que pode gerar desperdício e que não representa nenhuma agregação de valor ao produto final ou ao processo produtivo. Como por exemplo, apontamos uma máquina que está em operação com a sua capacidade produtiva subutilizada, o que gera desperdício de recursos.

O termo Mura refere-se ao aspecto da inconsistência e irregularidade, na medida que pode ser considerado como a "variação na operação de um processo que não foi causada pelo cliente". Como exemplo, podemos citar o desnivelamento ou desbalanceamento do trabalho ou máquina, ou seja, que esteja operando acima do normal.

O termo Muri está relacionado com a "sobrecarga causada na organização, equipamentos ou pessoas devido ao Muda e Mura". Desse modo, Silveira (2014) observa que de fato ocorre um processo em que as máquinas excedam a sua produção, ocorrendo problemas de quebras e defeitos. Já em relação às pessoas ocorre problema de segurança e baixa qualidade de vida e, por consequência, baixo desempenho. Uma organização (Silveira, 2014), faz-se prioritário sanar os problemas decorrentes dos 3Ms visto que estes consomem recursos de todos os tipos no contexto empresarial. Assim, a efetivação da melhoria contínua (Kaizen) permite que os 3Ms sejam identificados, diagnosticados e eliminados.

\subsection{Os 7 desperdícios}

Segundo a abordagem de Ohno (1997), o desperdício deve ser entendido "como um conjunto de elementos do processo produtivo que não agregam valor e geram aumento das despesas na organização". Desse modo, a eliminação do desperdício é o cerne para a diminuição dos custos para superar a competitividade atual no mercado.

Nesse sentido, os desperdícios estão trabalhados no Muda dos 3Ms Ohno (1997) e são classificados da seguinte forma:

- Defeitos

Esse desperdício ocorre quando algum item no processo de produção não atende aos requisitos mínimos de qualidade. Huntzinger (2005, p. 24) afirma que "problemas de qualidade geram os maiores desperdícios do processo". Ou seja, quando não se atende ao padrão de conformidade que é exigido no projeto gera o desperdício.

- Excesso de produção

O excesso de produção o problema ocorre quando a empresa está produzindo mais do que é necessário para atender a 
demanda de mercado. Conforme Corrêa e Corrêa (2004) quando a empresa produz de forma antecipada à sua demanda está, de fato, gerando um desperdício, visto que essa demanda pode não ser confirmada.

- Espera

Já o desperdício por espera ocorre no momento que os funcionários não estão sendo utilizados de forma produtiva por ficarem ociosos aguardando a chegada de material, por exemplo. De acordo com Corrêa e Corrêa (2004) os funcionários estão sendo pagos para ficarem ociosos.

- Transporte

Esse tipo de desperdício de transporte ocorre quando existe um deslocamento desnecessário dos equipamentos, dos documentos, dos suprimentos, das ferramentas ou ainda dos materiais. Segundo Ohno (1997) as grandes distâncias percorridas são um indicativo de que alguma coisa no layout não está adequada como deveria estar.

- Movimentação

Para esse tipo de desperdício, Ohno (1997) observa que acontece quando os operadores realizam movimentos desnecessários e que não agregam valor algum ao produto final ou ao processo produtivo. Além disso, esclarecem que muitos fatores podem provocar esse tipo de desperdício, como principalmente o ambiente desorganizado e o layout inadequado para realizar o processo produtivo de maneira eficiente.

- Processamento inapropriado

Os desperdícios de processamento destacam-se pelas atividades desenvolvidas, mas que não são necessárias para o produto atingir a qualidade indicada no projeto. De acordo com Antunes (2008) podem inclusive aumentar a qualidade para um nível não solicitado pelos clientes.

- Estoque

E, por último, o desperdício no caso de estoques acontece quando as empresas trabalham com níveis de estoques superiores ao mínimo necessário podendo ser de matéria-prima, produtos semiacabados ou acabados. Para Antunes (2008) o excesso de estoque é um custo a mais para a empresa, pois ocupa uma área e requer manutenção do inventário.

\subsection{Matriz Gravidade, Urgência e Tendência}

A matriz Gravidade, Urgência e Tendência (GUT) foi desenvolvida por Kepner e Tregoe, que são especialistas em resoluções de questões organizacionais Periard (2011). Esta é uma fermenta utilizada na priorização problemas que precisam ser tratados pela gestão.

Para Periard (2011) a matriz trabalha respondendo as questões do tipo "o que devemos fazer primeiro" ou "por onde devemos começar". A partir de uma relação dos fatos, mensurados com uma atribuição de pesos, conforme a gravidade dos problemas, busca-se classificá-los em termos de gravidade, urgência e tendência, conforme a classificação a seguir:

- Gravidade: identifica um dano nos resultados de médio e longo prazo;

- Urgência: indica a pressão do tempo para a resolução do problema;

- Tendência: sinaliza para o crescimento do problema ao longo do tempo.

Desse modo, para aplicar essa ferramenta é necessário seguir os seguintes passos:

- Elencar os problemas para análise;

- Pontuar o elemento pela intensidade;

- Multiplicar os valores atribuídos;

- Priorizar o ponto com maior resultado.

Assim, é possível conseguir priorizar os problemas de acordo com os fatores que mais pesam para a solução dos 
problemas, no contexto empresarial e do processo produtivo, especificamente.

\subsection{A Empresa Sousa}

A empresa, objeto de estudo deste trabalho, é do ramo alimentício com a fabricação de pão de queijo, atuando no mercado desde 2015, que ainda trabalha com uma estrutura familiar, contando apenas com dez funcionários tanto para a produção quanto para atividades administrativas.

A empresa vem crescendo ao longo dos anos e tem por objetivo produzir produtos de elevada qualidade, com preços competitivos no mercado. Além disso, prioriza o atendimento aos clientes e busca atender às suas demandas como eficiência visto que já tem entre seus clientes empresas e indústrias.

\subsection{Metodologia}

Esta seção apresenta os procedimentos metodológicos aplicados neste estudo, com o propósito de atingir os resultados de melhoria do processo fabril da Sousa. Foram estabelecidos no enquadramento metodológico: o objetivo da pesquisa; o tipo de pesquisa; o processo da pesquisa, examinando o processo produtivo da empresa e, por fim, a análise dos dados.

De acordo com Miguel (2010) para se definir o método de trabalho é preciso considerá-lo como um estudo de um fenômeno em um dado cenário, realizando interações com as pessoas, interligando a teoria com prática.

A presente pesquisa, de natureza aplicada, apresenta objetivo exploratório, pois exige-se do investigador informações sobre o que se deseja pesquisar, desde o levantamento bibliográfico, entrevistas com pessoas que vivenciam o dia a dia da Sousa (Pereira, 2018).

Desse modo, o procedimento deste trabalho foi caracterizado como pesquisa-ação, pois é um tipo de investigação social com base empírica que é concebida e realizada em estreita associação com uma ação ou com a resolução de um problema (Thiollent, 2005), conforme a representação na Figura 3, por propiciar o envolvimento colaborativo ou participativo do pesquisador no ambiente empresarial em estudo (Miguel, 2010).

Figura 3 - Fluxo da Pesquisa-Ação.

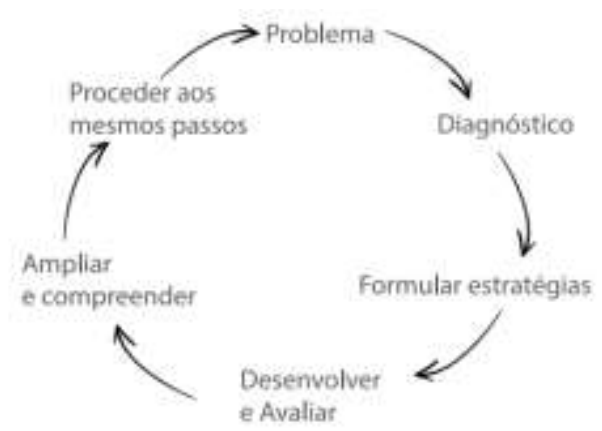

Fonte: Pereira (2018).

A abordagem deste estudo é quali-quantitativo (Pereira, 2018), pois foi iniciado com o mapeamento do processo produtivo, realizado pela observação in loco e obtida a partir de entrevistas com os envolvidos.

O segundo passo foi o diagnóstico do problema conforme apresentado no item 4.1.

\subsection{O processo produtivo}

O processo produtivo do pão de queijo é simples e tem seu ponto fundamental na mistura da massa e assamento nas condições ideias. Os ingredientes utilizados para a massa do pão de queijo são os seguintes: Polvilho, Queijo, Água, Óleo e 
Sal.

As etapas do processo do pão de queijo são as seguintes: Preparo dos ingredientes, Escaldamento, Mistura, Dosagem, Assamento, os equipamentos utilizados são: Peneiras, Balanças, Escaldador, Masseira, Dosadora de Formas, Forno a Lenha.

Além disso, como a empresa ainda tem uma produção diária relativamente pequena, ainda não precisa de um espaço físico muito grande para disposição dos equipamentos e preparo da massa.

A partir da observação do processo e informações obtidas com o responsável pela produção, que no caso é o proprietário da empresa, foi realizado um mapeamento do processo produtivo, que é apresentado conforme cada uma das etapas realizadas, conforme pode ser vista na Figura 3.

\subsection{Preparo dos ingredientes}

Para dar início ao processo de pesagem dos ingredientes é importante que todos estejam na temperatura ambiente. Para pesar o polvilho, o queijo e o sal é necessário que sejam peneirados antes, para garantir a uniformização do tamanho das partículas bem como facilitar a absorção de água.

\subsection{Escaldamento}

Essa etapa é de extrema importância para gelatinizar o amido para obter as características necessárias para o processamento. A partir desse processo a massa fica fácil de ser trabalhada e o produto fica macio, sendo assado em menos tempo e oferece melhor digestão do produto para os consumidores.

A empresa optou por empregar a mistura de água, óleo e sal, que é aquecida até a fervura para em seguida ser despejada sobre o polvilho dentro do escaldador, que realiza a mistura adequadamente dos ingredientes, favorecendo a hidratação do amido. Essa etapa é extremamente importante para garantir a qualidade dos produtos e a satisfação dos clientes.

\subsection{Masseira}

Essa etapa é que deve garantir a perfeita homogeneização dos ingredientes e a absorção adequada da umidade. Para isso é importante que a mistura escaldada seja resfriada à temperatura ambiente antes de ser levada à masseira.

É preciso avaliar a consistência da massa que deve se desenvolver nessa etapa para estar preparada para ser processada nos outros equipamentos. E por isso não pode estar esfarinhada e nem pegajosa. Tanto o tempo de mistura na masseira quanto a quantidade de água adicionada são apenas o necessário para a massa atingir o ponto ideal.

A empresa adotou o critério de adicionar os lipídios apenas ao final dessa etapa para facilitar a mistura e garantir uma boa absorção.

\subsection{Dosagem}

Nessa etapa, com a massa já preparada, ocorre a modelagem dos pães de queijo, ou seja, é dado o formato ao produto. Conforme explicações do proprietário a empresa iniciou realizando essa etapa enrolando manualmente cada um dos produtos. Mas, tinha problemas para controlar o tamanho e a pesagem de cada um dos pães de queijo.

Além disso, esclareceu que a aparência uniforme dos produtos depende diretamente do peso ideal e do tamanho padronizado para garantir o equilíbrio de assamento de todos os pães de uma mesma fornada. Pois se forem tamanhos diferentes pode ocorrer que alguns fiquem queimados e outros ainda crus.

Desse modo, a empresa passou a trabalhar com formas padronizadas que são semelhantes às utilizadas para fazer gelo, que todo mundo conhece e usa. Desse modo, padronizando o produto. 


\subsection{Assamento no forno a lenha}

Nessa etapa, o pão de queijo é assado no forno a lenha utilizando os quatro slots que estão em funcionamento. Desse modo, após ser assado já são embalados para atender as demandas diárias dos clientes e empresas.

A partir do mapeamento do processo produtivo foi possível desenvolver o seguinte fluxo de produção do pão de queijo.

Figura 4 - Fluxo de Produção do Pão de Queijo.

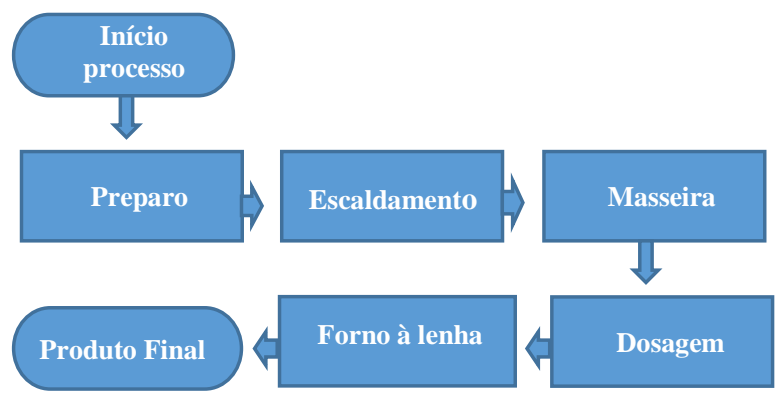

Fonte: Autores.

Como pode ser observado a partir da Figura 4, o processo de fabricação do pão de queijo é bastante simples e a empresa produz 1000 unidades por dia. O principal diferencial do produto é ser assado em fogo de lenha, que gera um fator de competitividade no mercado.

\subsection{Resultados e Discussões}

O mapeamento do processo produtivo da Fábrica de Pão de Queijo de São Paulo foi realizado ao acompanhar a execução do mesmo juntamente com o proprietário da empresa. Desse modo, foi possível identificar que estão ocorrendo alguns problemas de perdas na empresa. Com esse intuito foi realizada uma análise mais detalhada para levantar os possíveis desperdícios e sua localização no fluxo de produção, conforme a Figura 4.

Com os resultados obtidos constatou-se que existem desperdícios no que se refere à matriz Muda. Desse modo, é interessante apresentar no Quadro 1, os desperdícios encontrados e a sua descrição de forma clara e objetiva na empresa, bem como os sete desperdícios evidenciados pelo Muda.

Quadro 1 - Os desperdícios mapeados na Fábrica de Pão de Queijo.

\begin{tabular}{|c|c|}
\hline \multicolumn{2}{|r|}{ MUDA } \\
\hline 7 Desperdícios & Descrição do Desperdício \\
\hline 1. Defeitos & Os pães de queijo assados estão com problemas de qualidade \\
\hline 2. Excesso de produção & A produção diária é maior que a quantidade vendida \\
\hline 3. Espera & Não foi constatado desperdícios nesse item \\
\hline 4. Transporte & Não foi constatado desperdícios nesse item \\
\hline 5. Deslocamento & O operador realiza movimentos desnecessários com o produto \\
\hline 6. Processo inapropriado & Subutilização do forno a lenha \\
\hline 7. Estoque & Não foi constatado desperdícios nesse item \\
\hline
\end{tabular}

Fonte: Autores.

Conforme pode ser observado no Quadro 1 foram identificadas as situações desfavoráveis na empresa, especificamente no fluxo de produção do pão de queijo. E, desse modo, fica fácil perceber que esses 4 desperdícios levantados provocam impactos negativos para a fábrica acarretando um aumento dos custos de fabricação e na perda de clientes. 
Além disso, desenvolveu-se uma análise mais detalhada para identificar dos quatro desperdícios identificados quais apresentavam maior impacto negativo no aspecto financeiro da empresa.

Desse modo, foram analisadas as informações mapeadas relacionadas aos problemas identificados e elaborada a matriz GUT, que tem a função de indicar quais são os desperdícios que necessitam de uma solução com agilidade, objetivando elevar o retorno financeiro para a fábrica.

Quadro 2 - Matriz GUT.

\begin{tabular}{|l|c|c|c|c|c|}
\hline Desperdício & Gravidade & Urgência & Tendência & Total & Classificação \\
\hline $\begin{array}{l}\text { Subutilização do forno } \\
\text { a lenha }\end{array}$ & 4 & 4 & 3 & 48 & $1^{\circ}$ \\
\hline $\begin{array}{l}\text { A produção diária é } \\
\text { maior que a quantidade } \\
\text { vendida }\end{array}$ & 4 & 4 & 3 & 36 & $2^{\circ}$ \\
\hline $\begin{array}{l}\text { O operador realiza } \\
\text { movimentos } \\
\text { desnecessários na } \\
\text { produção }\end{array}$ & 3 & 4 & 2 & 24 & $3^{\circ}$ \\
\hline $\begin{array}{l}\text { Os pães de queijo } \\
\text { assados estão com } \\
\text { problemas de qualidade }\end{array}$ & 1 & 1 & 1 & 1 & $4^{\circ}$ \\
\hline
\end{tabular}

Fonte: Autores.

Os critérios utilizados para a classificação da matriz GUT foram os seguintes, conforme Quadro 3.

Quadro 3 - Critérios da matriz GUT.

\begin{tabular}{|c|l|l|l|}
\hline Nota & \multicolumn{1}{|c|}{ Gravidade } & \multicolumn{1}{c|}{ Urgência } & \multicolumn{1}{c|}{ Tendência } \\
\hline 5 & Extremamente grave & Precisa de ação imediata & Irá piorar rapidamente \\
\hline 4 & Muito grave & Muito urgente & Irá piorar a curto prazo \\
\hline 3 & Grave & $\begin{array}{l}\text { Urgente, merece atenção no } \\
\text { curto prazo }\end{array}$ & Irá piorar a médio prazo \\
\hline 2 & Pouco grave & Pouco urgente & Irá piorar a longo prazo \\
\hline 1 & Sem Gravidade & Pode esperar & Não irá mudar \\
\hline
\end{tabular}

Fonte: Autores.

Conforme a pontuação obtida com a matriz GUT os três desperdícios de maior impacto negativo para a fábrica foram identificados como sendo:

- A subutilização do forno a lenha;

- A produção diária é maior do que a quantidade vendida;

- O operador realiza movimentos desnecessários na produção.

De fato, o problema com o excesso de produção precisa ser resolvido com urgência para evitar impactos financeiros mais graves para a empresa. O problema é que a metade dos slots do forno estão apresentando defeitos e não estão sendo utilizados. Por isso a capacidade de produção está reduzida em $50 \%$, pois apenas 4 slots são utilizados e desse modo caracteriza-se a subutilização da capacidade instalada do forno a lenha.

Em função desse problema com os slots, a produção diária ocorre com uma sobra de 160 unidades, pois precisa assar conforme os horários agendados para realizar a entrega ao cliente do produto ainda quentinho.

Já em relação aos movimentos desnecessários do operador foi constatado que são movimentos que não agregam valor ao produto final e podem ser eliminados sem qualquer problema para o processo produtivo. 
Quanto ao desperdício relacionado com os pães de queijo assados estão com problemas de qualidade ocorre porque a empresa utiliza dosadores de forma ao invés de equipamentos dosadores, que oferecem uma maior qualidade.

Os equipamentos dosadores são os mais recomendados, pois formam a massa na gramatura desejada e cortam também. Estes equipamentos são trabalhados com bandejas ou um padrão mais sofisticado que é cortar os pães na esteira que conduz ao armário para congelamento. No entanto, como é um custo que a empresa no momento não pode realizar e o problema já está sendo contornado com maior cuidado no processo produtivo não será objeto de análise neste estudo.

Portanto, analisando os quatro desperdícios identificados decidiu-se por aplicar a metodologia Kaizen nos três desperdícios que necessitam de uma solução mais imediata por impactar financeiramente de forma negativa a fábrica e que são muito relacionados.

\subsection{A melhoria do forno da fábrica de pão de queijo de São Paulo}

A fábrica de pão de queijo de São Paulo utiliza um forno a lenha com capacidade de oito slots, correspondendo a oito formas de 60 pães de queijo cada uma. Desse modo, em uma fornada são produzidas 480 unidades de pão de queijo. Assim, considerando que a produção diária da fábrica é de 800 unidades apenas com duas fornadas atenderia a sua demanda.

No entanto, o problema é que apenas 4 dos 8 slots estão sendo utilizados e, por este motivo, a capacidade produtiva do forno está sendo subutilizada em 50\% e aumentando os custos de produção, pois ao invés de apenas duas fornadas são necessárias 4 fornadas para atender a demanda de 800 unidades diárias.

Foram desenvolvidas reuniões com o proprietário e os funcionários para uma avaliação conjunta da melhor alternativa de solucionar o problema da utilização de apenas 4 dos 8 slots do forno. Foi constatado que, para resolver o problema uma solução inicial, seria realizar uma limpeza nos slots que não estão funcionando para identificar precisamente o problema.

Tanto os funcionários quanto o proprietário ponderaram que a dificuldade para realizar essa limpeza é a produção consecutiva nos sete dias da semana. Pois é necessário atender a demanda de empresas que trabalham com turnos e de forma ininterrupta.

A partir dessas considerações a solução encontrada em conjunto com os funcionários e o proprietário foi de realizar a limpeza do forno em um dia após a última fornada do dia e estendendo para além do horário de serviço. Inclusive, essa foi uma sugestão apresentada pelos funcionários que já conhecem o forno e estão aptos a realizar o processo.

Desse modo, o passo seguinte foi identificar qual seria o melhor dia da semana, em que a última fornada termina mais cedo e permite a limpeza. A partir dessa constatação identificou-se que o melhor dia é o sábado, principalmente porque a primeira fornada de domingo é um pouco mais tarde.

Para realizarem a limpeza os funcionários reuniram os materiais necessários como chaves de fenda, desentupidores de bico, sabão, panos e buchas. $\mathrm{O}$ trabalho dos funcionários foi realizado e estendeu-se por quase 4 horas, sendo acompanhado e auxiliado pelo proprietário e pelos pesquisadores.

Após a limpeza constatou-se que dos quatro slots apenas um estava com uma haste quebrada que precisava de conserto, sendo que as outras estavam bastante obstruídas e enferrujadas.

O trabalho de limpeza foi realizado em equipe, em que parte cuidava de desentupir os slots, outros cuidavam de fazer o conserto da haste quebrada usando um soldador profissional.

Concluindo o trabalho, fizeram um teste ligando os slots e deixando funcionar por cerca de 10 minutos. Os resultados foram muito satisfatórios e no dia seguinte já seria possível utilizar todos nas fornadas do dia.

\subsection{A produção diária é maior do que a quantidade vendida}

Esse desperdício, que consistia em 160 unidades por dia, foi discutido em uma reunião dos funcionários com o 
proprietário e os pesquisadores. Com todos os slots funcionando a produção por fornada passa a ser de 480 unidades efetivamente.

Contudo, como a empresa precisa manter as fornadas agendadas conforme os horários de atendimento uma alternativa identificada pelos funcionários foi realizar um contato com todos os clientes para rediscutir os horários de entregas com o objetivo de tentar estabelecer um horário mais ou menos padrão, que atendesse a todos os clientes.

Além disso, o proprietário animado com a solução do problema da subutilização do forno decidiu prospectar potenciais clientes para realizar novas vendas como passar a comercializar o produto diretamente ao consumidor com uma pequena loja de atendimento presencial e online.

\subsection{Novo layout para eliminar movimentos desnecessários}

A partir de uma observação in loco da movimentação dos operadores na área de produção foi possível identificar a sequência de movimentos bem como a distância percorrida em cada movimento. Além disso, a movimentação em relação a cada etapa do processo produtivo a ser realizado foi observada.

Foi constatado uma desordem existente entre um processo e outro, pois ocorre um grande deslocamento sem necessidade entre os equipamentos. A partir da quantificação dos movimentos constatou-se que os operadores percorrem uma distância de 48m do início do processo até o produto final, conforme o fluxo de trabalho apresentado a seguir.

Figura 5 - Fluxo de trabalho de $48 \mathrm{~m}$.

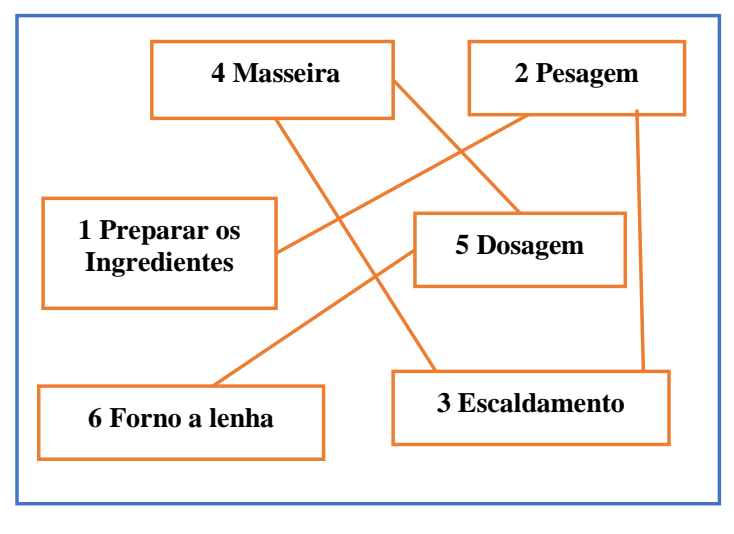

Fonte: Autores.

Após reuniões com os funcionários analisando esse fluxo de movimentação e visando reduzir movimentos para otimizar a produção chegou-se a concepção de uma nova disposição dos equipamentos do processo produtivo.

Essa nova disposição tem por objetivo facilitar e agilizar o deslocamento dos padeiros considerando que os equipamentos foram alocados de acordo com a sua ordem de processamento, diminuindo a movimentação do produto em produção.

Com esse novo arranjo físico o percurso dos padeiros passou para 26m considerando o processo do seu início até o final, o que ofereceu um processo mais ágil e otimizado, conforme o novo fluxo de trabalho apresentado a seguir 
Figura 6 - Fluxo de trabalho de 26m.

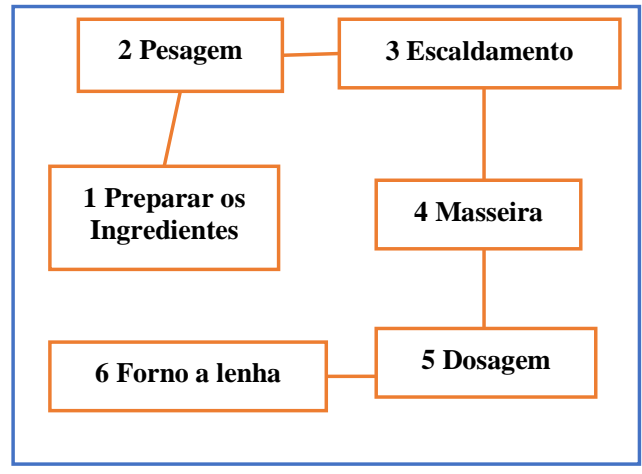

Fonte: Autores.

A partir da mudança do arranjo físico foi possível realizar uma redução de $48 \mathrm{~m}$ para $26 \mathrm{~m}$ no fluxo do processo produtivo, sendo que corresponde a uma diminuição de $46 \%$ da movimentação dos funcionários e materiais, consequentemente foi diminuído o tempo de processos.

Assim como é importante frisar que o forno a lenha não teve sua localização alterada devido a problemas de espaço físico que implicaria em custos para a empresa com a reforma do ambiente. Mas, se não fosse essa limitação as vantagens poderiam ter sido maior com o novo layout. Desse modo, a melhor opção foi mudar os equipamentos, otimizando o processo e não gerando custos para a empresa com esse novo arranjo.

\subsection{Conclusão}

O objetivo deste trabalho foi desenvolver um estudo de caso para identificar os desperdícios da empresa Souza e propor soluções para eliminá-los. Desse modo, o trabalho consistiu na implementação de melhorias a partir das metodologias trabalhadas de 3Ms e Kaizen.

É importante salientar, como que, a partir dessas metodologias foi possível incrementar os resultados positivos para a empresa, sem incorrer em custos. De fato, foram realizadas mudanças a partir do trabalho conjunto entre funcionários e proprietário para que fosse encontrada a melhor solução para a empresa.

A grande relevância deste trabalho foi ter desenvolvido um plano de ação conjuntamente com os funcionários e proprietários, gerando benefícios tanto para a empresa quanto para as pessoas envolvidas. Apesar do resultado satisfatório, ainda existe a chance de estabelecer novas melhorias para tornar mais eficiente o processo operacional e administrativo, com revisões periódicas de manutenção dos equipamentos, desenvolvimento estratégico da missão, visão e valores da organização, a fim da continuidade do negócio.

\section{Referências}

Almeida, M. R., Belo, J. N. \& Silva, B. C. (2011). Evento Kaizen: Estudo de caso em uma metalúrgica brasileira. http://www.abepro.org.b r/biblioteca/enegep2011_TN_STO_135_855_19126.pdf.

Antunes, J. (2008). Sistemas de Produção: Conceitos e práticas para projeto e gestão de produção enxuta. Bookman.

Corrêa, H. L. \& Corrêa, C. A. (2004). Administração da Produção e Operações: Manufatura e Serviços - uma abordagem estratégica. (4a ed.), Atlas.

Kondrasovas, D. (2020). Casa Sistema Toyota. https://davidkond.wordpress.com.

Huntzinger, J. (2005). As raízes do Lean. www.lean.org.br/bases.php?interno=comunidade_artigos

Imai, M. (1996). Gemba-Kaizen: estratégias e técnicas do Kaizen no piso de fábrica. Iman

Kanbanize, (2020). Muda, Mura e Muri. https://kanbanize.com/pt/gestao-lean/valor-desperdicio/7-desperdicios-do-lean. 
Research, Society and Development, v. 10, n. 6, e57710616138, 2021

(CC BY 4.0) | ISSN 2525-3409 | DOI: http://dx.doi.org/10.33448/rsd-v10i6.16138

Liker, J. K. (2005) O modelo Toyota: 14 princípios da gestão da maior fabricante do mundo. Bookman.

Meireles, M. (2001). Ferramentas Administrativas para identificar, observar e analisar problemas: organizações com foco no cliente. Arte \& Ciência.

Miguel, P.A.C. (2010). Metodologia de Pesquisa em Engenharia de Produção e Gestão de Operações. (2a ed.) Campus.

Ohno, T. (1997). O Sistema Toyota de Produção: Além da produção em larga escala. Bookman.

Pereira, A. S., Shitsuka, D. M., Parreira, F. J., \& Shitsuka, R. (2018). Metodologia da pesquisa científica. http://repositorio.ufsm.br/handle/1/15824.

Periard, G. (2011). Matriz Gut, http://www.sobre administracao.com/matrizgut-guia-completo/.

Sehleanu, M. \& Flore, E.-S. (2019). Continuous Improvement Through Kaizen Management System: A Case Study. Proceedings of the International Management Conference, Faculty of Management, Academy of Economic Studies, Bucharest, Romania, 13(1), 25-36, https://ideas.repec.org/a/rom/mancon/v13y2019i1p25-36.html.

Sharma, P., Sharma, N. K. \& Singh, M. (2015). Process Improvement by Implementation of Kaizen as a Quality Tool within defined constraints: A case study in Manufacturing Industry. Matter: International Journal of Science and Technology, 1(1), 182-194. https://doi.org/10.20319/mijst.2016.s11.182194

Shingo, S. (2005). O Sistema Toyota de Produção: Eng. de Produção. (3a. ed.), Artes Médicas.

Silva, M. G. \& Santos, A. R. (2010). Conceitos e práticas da automação em uma empresa eletrônica brasileira: um estudo de caso. Encontro Nacional de Eng. de Produção, São Carlos.

Silveira, C. B. (2014). Muda, Mura e Muri: O modelo $3 M$ do sistema Toyota. https://www.citisystems.com.br/muda-mura-muri/.

Thiollent, M. (2005). Metodologia da pesquisa-ação. (18a. ed.), Cortez.

Womack, J. P., Jones, D. T. \& Roos, D. (2007). The machine that changed the world. Free Press. 